\title{
М.Ю. Кузьмин
}

\author{
Иркутский государственньй университет (Иркутск, Россия) \\ Динамика связи компонентов идентичности \\ и ее статусов у студентов
}

\begin{abstract}
Рассматриваются отечественные и зарубежные подходы к динамике статусов идентичности и отдельных ее компонентов. Изучается специфика связей между различными компонентами идентичности и статусами эгоидентичности. В ходе исследования обнаруживаются тендениии к изменению статусов идентичности. На первом этапе обучения большинство связей компонентов идентичности приходится на статус Достигнутой идентичности. $B$ дальнейшем они в большей степени связаны со статусом Предрешенной и Спутанной (второй срез), Спутанной (третий срез) идентичности.
\end{abstract}

Ключевые слова: эго-идентичность; идентичность; юноши; студенты; «Двадиать утверждений»; статусы идентичности.

Проблема идентичности, особенностей ее развития и кризиса широко изучается в зарубежной и отечественной психологии. Одним из подходов являются предложенная Э. Эриксоном теория эго-идентичности и разработанная затем Дж. Марсиа статусная модель эго-идентичности. Статусная модель эго-идентичности по праву считаеся классической и неоднократно обсуждалась как в отечественной [1], так и в зарубежной психологии [2-4].

Согласно представлениям Дж. Марсиа [2], статус идентичности складывается из соотношения состояния поиска идентичности (Exploration) и уровня ее согласованности (наличие или отсутствие единиц идентичности - личностно значимых целей, ценностей, убеждений, commitments). Таким образом, можно выделить диффузную идентичность (diffusion - минимум поиска идентичности и минимум ее согласованности), предрешенную идентичность (foreclosure - высокий уровень согласованности идентичности при минимуме поиска), moratorium (высокий уровень поиска идентичности, но ее нестабильность) и достигнутуюя идентичность (высокий уровень согласованности идентичности после высокой интенсивности ее поиска).

В современной западной психологии модель Дж. Марсиа пересматривается (напр., [3-5]) за счет дополнения новых компонентов. Расширение модели Марсиа позволило выделить новые промежуточные статусы идентичности (раннее закрытие (early closure), мораторий, сопровождающийся поиском (searching moratorium) и т.п.), а также привело к исследованиям, направленным на анализ путей развития идентичности [6]. В ре- 
зультате была создана методика Utrecht-Management of Identity Commitments Scale (U-MICS), которая позволяла изучать изменения статусов идентичности в различных сферах - традиционно выделяемых социальных группах (обозначается авторами как идеологическая сфера - школа, профессия, ценности) и в малых группах (relational; например, межличностные отношения с семьей, друзьями и т.д.) [3].

В отечественной психологии статусная модель Дж. Марсиа использовалась при изучении различных видов идентичности Л.Б. Шнейдер при помощи разработанных ею на основе метода свободных ассоциаций методик (МИЛИ - методика изучения личностной идентичности; МИПИ - методика изучения профессиональной идентичности) [7]. Е.Л. Солдатова, изучая проблему кризиса идентичности взрослости, также использовала модель Дж. Марсиа, выделяя на ее основе только три статуса - достигнутой идентичности, спутанной и предрешенной [8].

Вместе с тем, кроме ограниченного числа методик, направленных на изучение отдельных компонентов идентичности (профессиональный, гендерный), методики для изучения развития отдельных сторон идентичности с точки зрения ее статусной модели в отечественной практике не используются. По нашему мнению, первым шагом для изучения данного вопроса может стать изучение связей между различными компонентами идентичности и статусами эго-идентичности. Такие исследования проводились в зарубежной науке (помимо упомянутых выше) $[9,10]$. Однако данные работы не затрагивали динамику связей между компонентом идентичности и ее статусом, не носили лонгитюдного характера. В этой связи мы решили изучить, насколько связаны изменения в самоидентификации и различные статусы эго-идентичности в юношеском возрасте.

\section{Материалы и методики исследования}

Исследование проводилось в период с 2013 по 2017 г. на выборке юношей и девушек - студентов и студенток различных факультетов Иркутского государственного университета - и охватывало период их обучения по программе бакалавриата (4 года). В начале исследования число испытуемых составляло 250 (112 юношей и 138 девушек). На заключительном этапе исследования число испытуемых сократилось до 220 (99 юношей и 121 девушка). Процент выбывших в ходе исследования, таким образом, составил $12 \%$. Причинами исключения из исследования стали академический отпуск, отчисление из вуза, перевод на другой факультет и т.д.

Для изучения выраженности различных компонентов идентичности в юношеском возрасте использовалась методика «Двадцать утверждений» М. Куна и Т. МакПартленда [11]. Для исследования статусов эгоидентичности использовалась методика СЭИ-тест Е.Л. Солдатовой [8]. При рассмотрении динамики результатов использовались t-критерий Стьюдента, нормализованный z-критерий, а также критерий корреляции Спирмена. 


\section{Анализ данных}

На первом этапе мы проанализировали динамику отдельных компонентов идентичности в юношеском возрасте в период с 2013 по 2017 г. (соответствует курсу обучения студентов в рамках программы бакалавриата, табл. 1).

Т а бл и ц а 1

\section{Динамика отдельных компонентов идентичности юношей}

\begin{tabular}{|l|c|c|c|c|c|c|c|c|}
\hline \multirow{2}{*}{\multicolumn{1}{|c|}{ Компонент }} & \multicolumn{2}{c|}{ 1-й курс } & \multicolumn{2}{c|}{ 2-й курс } & \multicolumn{2}{c|}{ 3-й курс } & \multicolumn{2}{c|}{ 4-й курс } \\
\cline { 2 - 10 } & Число & $\%$ & Число & $\%$ & Число & $\%$ & Число & $\%$ \\
\hline Поло-ролевой & 214 & 4,8 & 209 & 5,1 & 229 & 5,2 & 235 & 5,3 \\
\hline $\begin{array}{l}\text { Учебно- } \\
\text { профессиональный }\end{array}$ & 280 & 6,3 & 301 & 7,3 & 219 & 5,0 & 312 & 7,0 \\
\hline Семейный & 421 & 9,5 & 464 & 11,2 & 537 & 12,3 & 567 & 12,7 \\
\hline Этнический & 98 & 2,2 & 134 & 3,2 & 123 & 2,8 & 113 & 2,5 \\
\hline Личностный & 2127 & 49,0 & 1914 & 46,2 & 2028 & 47,4 & 2021 & 45,4 \\
\hline Коммуникативный & 195 & 4,4 & 175 & 4,2 & 183 & 4,2 & 170 & 3,8 \\
\hline Деятельностный & 236 & 5,3 & 187 & 4,5 & 177 & 4,1 & 173 & 3,9 \\
\hline Перспективный & 40 & 0,9 & 28 & 0,7 & 39 & 0,9 & 89 & 2,0 \\
\hline Групповой & 152 & 3,4 & 142 & 3,4 & 138 & 3,2 & 119 & 2,7 \\
\hline Экзистенциальный & 621 & 14,0 & 593 & 14,3 & 657 & 15,0 & 649 & 14,6 \\
\hline
\end{tabular}

Прежде всего обращает на себя внимание отсутствие серьезных изменений в структуре идентичности в целом на всем протяжении обучения в вузе - с 1-го по 4-й курс. Основное место в ней занимает личностный компонент - на него приходится от 49\% (на 1-м курсе) до 45,5\% (4 курс) всех ответов испытуемых. Также существенную долю всех ответов испытуемых занимают экзистенциальный (14-15\%), семейный $(9,5-12,7 \%)$, учебно-профессиональный (5-7,3\%) компоненты.

Во-вторых, динамика ряда компонентов идентичности имеет неравномерный характер. Так, выраженность учебно-профессионального компонента значимо снижается к 3-му курсу (с 7,3 до 5\%, $Z=2,89, \mathrm{p}<0,01$ ), однако затем резко повышается (с 5 до 7\%, $Z=2,91, \mathrm{p}<0,01$ ). Выраженность перспективного компонента идентичности также первоначально снижается, однако к окончанию вуза значимо возрастает (с 0,9 до 2\%, $\mathrm{Z}=3,54, \mathrm{p}<0,01)$.

В-третьих, ряд компонентов демонстрирует устойчивую повышательную либо понижательную динамику, которая от курса к курсу не является значимой. Так, семейная идентичность устойчиво растет на всем протяжении студенчества (с 9,5 до $12,7 \%, Z=3,84, \mathrm{p}<0,01)$. Наоборот, описание себя в терминах членства в различных неформальных группах более свойственно первокурсникам, чем выпускникам (снижение с 3,4 до 2,7\%, $\mathrm{Z}=2,77, \mathrm{p}<0,01)$.

В целом можно заключить, что динамика компонентов идентичности в юношеском возрасте незначительна. На временном периоде в один 
год различия могут отсутствовать вовсе. Между тем на более широких промежутках можно говорить об определенных тенденциях в идентичности. Так, семейная идентичность устойчиво растет на всем протяжении студенчества; описание себя в терминах членства в различных неформальных группах, как и деятельностная идентичность, имеет тенденцию к снижению; экзистенциальный компонент идентичности незначительно меняется как в сторону увеличения доли, так и в сторону ее снижения.

На втором этапе мы проанализировали динамику статусов идентичности студентов, измеренной по методике СЭИ-тест (табл. 2).

Т а б ли ц а 2

Динамика статусов эго-идентичности в юношеском возрасте

\begin{tabular}{|c|c|c|c|c|}
\hline \multicolumn{2}{|c|}{ Статусы идентичности } & Достигнутая & Спутанная & Предрешенная \\
\hline \multirow{4}{*}{ 1-й курс } & $\mathrm{m}$ & 26,44 & 11,19 & 12,80 \\
\hline & $\sigma$ & 4,97 & 4,96 & 3,89 \\
\hline & t-критерий & - & - & - \\
\hline & р-уровень & - & - & - \\
\hline \multirow{4}{*}{ 2-й курс } & $\mathrm{m}$ & 26,55 & 12,10 & 11,36 \\
\hline & $\sigma$ & 5,30 & 4,85 & 3,74 \\
\hline & t-критерий & - & - & 2,05 \\
\hline & р-уровень & - & - & 0,05 \\
\hline \multirow{4}{*}{ 3-й курс } & $\mathrm{m}$ & 21,72 & 15,38 & 12,91 \\
\hline & $\sigma$ & 5,26 & 4,75 & 4,29 \\
\hline & t-критерий & 3,44 & 3,02 & - \\
\hline & р-уровень & 0,01 & 0,01 & - \\
\hline \multirow{4}{*}{ 4-й курс } & $\mathrm{m}$ & 22,70 & 13,65 & 13,65 \\
\hline & $\sigma$ & 5,52 & 5,61 & 4,57 \\
\hline & t-критерий & - & - & - \\
\hline & р-уровень & - & - & - \\
\hline
\end{tabular}

Как следует из табл. 2, по сравнению с первым курсом у студентов ко второму курсу снижается выраженность статуса Предрешенной идентичности $(\mathrm{t}=2,05, \mathrm{p}<0,02)$. Затем, к третьему курсу, наблюдаются драматическое падение выраженности статуса Достигнутой идентичности и, наоборот, значимый рост статуса Спутанной идентичности $(\mathrm{t}=3,44, \mathrm{t}=$ $3,02$ соответственно, $\mathrm{p}<0,01)$. Наконец, по сравнению с третьим курсом на четвертом курсе никаких значимых изменений по шкалам методики СЭИтест не отмечается.

Таким образом, кризис структуры эго-идентичности наблюдается у студентов между 2-м и 3-м курсами. При этом между 1-м и 2-м, наоборот, наблюдается снижение выраженности статуса Предрешенной идентичности, связанной, возможно, с постепенным вхождением студентов в учебный процесс в частности и в новую для себя социальную роль вообще, однако это снижение компенсируется постепенным ростом статуса Спутанной идентичности.

При этом динамика статусов эго-идентичности у студентов, измеренная нами при помощи методики СЭИ-тест, несколько отличается от 
смены статусов, предложенной в модели Дж. Марсиа: статус диффузной (спутанной) идентичности - мораторий - статус предрешенной идентичности - статус достигнутой идентичности (по Meeus, 2011). На наш взгляд, это связано с тем, что, во-первых, в модели Е.Л. Солдатовой не выделяется статус моратория. Во-вторых, наши наблюдения ограничиваются 4-летним периодом и завершаются вместе с окончанием студентами бакалавриата, т.е. в момент, драматический для их идентичности. Можно предположить, что вслед за снижением выраженности Достигнутой идентичности наступит статус моратория и затем - через Предрешенную идентичность испытуемые вновь обретут статус Достигнутой идентичности уже в новом для себя статусе - как представители определенной профессии или как студенты-магистранты. Тем не менее смена статусов идентичности у студентов в нашем исследовании не оказалась столь линейной и столь явно выраженной.

На третьем этапе мы проанализировали корреляции, существующие между отдельными компонентами идентичности и шкалами методики СЭИ-тест (табл. 3).

В первый год полоролевой компонент идентичности не обнаруживает никаких корреляций со шкалами методики СЭИ-тест. Однако уже на втором году обнаруживается отрицательная связь со статусом Достигнутой идентичности $(\rho=-0,36, p<0,01)$ и положительная - со статусом Предрешенной идентичности $(\rho=0,39, \mathrm{p}<0,01)$. В дальнейшем поло-ролевой компонент идентичности обнаруживает отрицательную корреляцию на уровне тенденции со статусом Достигнутой идентичности $(\rho=-0,17, \mathrm{p}<$ $0,05)$ и положительную - со Спутанной идентичностью $(\rho=0,24, p<0,01)$. Наконец, к концу обучения студентов связь сохраняется на уровне тенденции - положительная со статусом Достигнутой идентичности $(\rho=0,19, \mathrm{p}<$ $0,01)$ и отрицательная - со Спутанной $(\rho=-0,18, \mathrm{p}<0,05)$.

Как мы отмечали при анализе числа идентификаций, приходящихся на тот или иной компонент идентичности, доля полоролевой идентичности практически не меняется в течение всей учебной деятельности испытуемых. При этом выраженность у них различных статусов идентичности, наоборот, отличается повышенной динамикой - особенно между 2-м и 3-м курсами. Согласно выделенным корреляциям, можно сделать вывод, что стабильность полоролевого компонента оказывается более свойственной испытуемым, у которых ко 2-му курсу происходит кризис эго-идентичности: сначала снижается выраженность статуса Достигнутой идентичности при одновременном росте выраженности статуса Предрешенной идентичности, а затем рост выраженности Спутанной идентичности.

Учебно-профессиональный компонент идентичности во всем периоде обучения обнаруживает тесные связи со статусами эго-идентичности. 


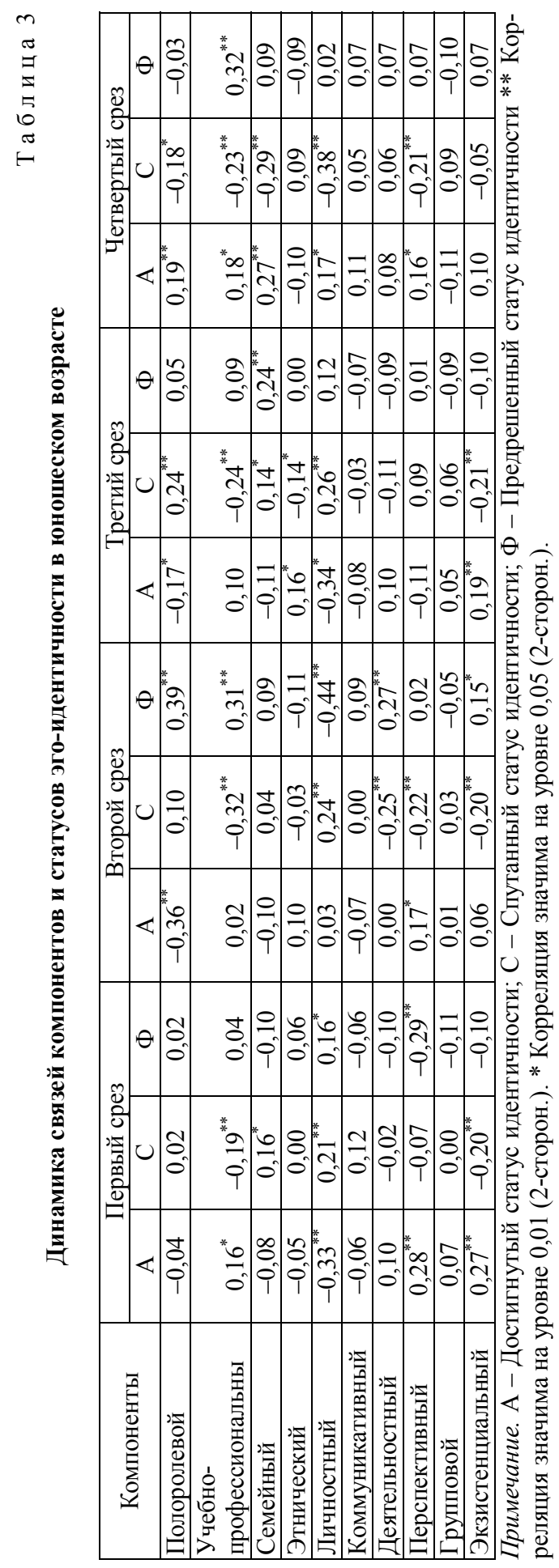


В начале обучения эти связи носят характер тенденции: выраженный учебный компонент положительно коррелирует со статусом Достигнутой идентичности $(\rho=0,16, \mathrm{p}<0,05)$ и отрицательно - со статусом Спутанной $(\rho=-0,19, p<0,01)$. Однако уже на второй год обнаружены выраженные корреляции: положительная - со статусом Предрешенной идентичности $(\rho=-0,31, p<0,01)$ и отрицательная - со статусом Спутанной идентичности $(\rho=-0,32, p<0,01)$. В следующем году обнаружена только корреляция со статусом Спутанной идентичности $(\rho=-0,24, \mathrm{p}<0,01)$. Наконец, к концу обучения в вузе у учебно-профессионального компонента зафиксированы корреляции со всеми статусами эго-идентичности - положительная - с Достигнутым $(\rho=0,18, p<0,05)$ и Предрешенным $(\rho=0,32, p<0,01)$ статусами и отрицательная - со Спутанной идентичностью $(\rho=-0,23, \mathrm{p}<0,01)$.

Учитывая динамику учебно-профессионального компонента во всем периоде обучения, можно предположить следующее. Постепенное овладение профессией и развитие профессиональной идентичности предполагают смену ее статусов: первоначально данный компонент положительно коррелирует с Достигнутой идентичностью и отрицательно со Спутанной, однако по мере овладения профессией и развития собственно профессиональной идентичности наблюдается появление корреляций с Предрешенной идентичностью. К концу обучения в вузе можно предположить формирование у ряда студентов собственно профессиональной идентичности (положительная корреляция с Достигнутой идентичностью); у части испытуемых она осталась в статусе Предрешенной.

В первые годы обучения в вузе корреляции между семейным компонентом идентичности и статусами эго-идентичности практически отсутствуют (исключение - положительная связь на уровне тенденции со статусом Спутанной идентичности на первом году обучения $(\rho=0,16, \mathrm{p}<0,05)$. Однако на третьем году обучения зафиксирована положительная связь на уровне тенденции как со статусом Спутанной идентичности ( $\rho=0,14$, $\mathrm{p}<0,05)$, так и со статусом Предрешенной идентичности $(\rho=0,24$, $\mathrm{p}<0,01)$. Наконец, к концу обучения в вузе присутствует как положительная связь со статусом Достигнутой идентичности $(\rho=0,27, \mathrm{p}<0,01)$, так и отрицательная - со статусом Спутанной идентичности $(\rho=-0,29, p<0,01)$. Можно предположить, что, как и в случае учебно-профессиональной идентичности, к концу обучения в вузе у студентов происходит перестройка соответствующего компонента идентичности. Однако она не так отражается в изменении числа самоописаний: испытуемые продолжают описывать себя в соответствующих категориях и в ходе трансформации данной идентичности - отсюда положительная связь со статусом Предрешенной идентичности на третьем году обучения.

Динамика связей этнического компонента идентичности и статусов эго-идентичности не столь выражена. Можно отметить только положительную связь на уровне тенденции на третьем году обучения со статусом Достигнутой идентичности $(\rho=0,16, p<0,05)$ и отрицательную - со статусом Спутанной $(\rho=-0,14, p<0,05)$. Можно предположить, что с учетом 
резкого снижения Достигнутой идентичности в целом у студентов в этот период и резкого роста Спутанной идентичности этнический компонент оказывается своеобразной точкой опоры для некоторых испытуемых.

Личностный компонент оказывается самым выраженным у испытуемых, и, возможно, за счет этого динамика корреляционных связей со шкалами методики СЭИ-тест у этого компонента наиболее выраженная. С одной стороны, при первом срезе обнаруживается отрицательная корреляция между данным компонентом и статусом Достигнутой идентичности $(\rho=-0,33, p<0,01)$. При этом связи со статусами Предрешенной и Спутанной идентичности положительны ( $\rho=0,21, \rho=0,16$ соответственно, $\mathrm{p}<0,05)$. Однако уже на втором году обучения сохраняется положительная связь со статусом Спутанной идентичности $(\rho=0,24, \mathrm{p}<0,01)$, а корреляция со статусом Предрешенной идентичности оказывается отрицательной $(\rho=-0,44, p<0,01)$. Можно предположить, что в ситуации спутанной эгоидентичности испытуемые чаще описывают себя при помощи личностных характеристик.

На третьем году обучения зафиксирована отрицательная корреляция между данным компонентом и статусом Достигнутой идентичности $(\rho=-0,34, p<0,01)$ и положительная - со статусом Спутанной идентичности $(\rho=0,26, p<0,01)$. Наконец, в конце обучения зафиксирована положительная корреляция со статусом Достигнутой идентичности на уровне тенденции $(\rho=0,17, p<0,05)$ и отрицательная - со статусом Спутанной идентичности $(\rho=-0,38, p<0,01)$.

В одном из наших предыдущих исследований мы указывали, что выраженный личностный компонент идентичности в юношеском возрасте указывает на выраженность кризиса идентичности. Получается, что только к концу обучения в вузе связь между самоописанием себя в категориях личностной идентичности перестает быть связанной со Спутанным статусом положительно, а личностный компонент - отражать кризис идентичности на данном этапе.

Ни с коммуникативным, ни с деятельностным компонентом идентичности связь статусов эго-идентичности не является определенной. Только на втором году обучения отмечаются связи между деятельностным компонентом и статусами Спутанной $(\rho=-0,36, \mathrm{p}<0,01)$ и Предрешенной $(\rho=0,27, p<0,01)$ идентичности: описание студентами себя в категориях определенных занятий негативно связано со Спутанной и позитивно - с Предрешенной идентичностью.

Перспективный компонент идентичности коррелирует со шкалами методики СЭИ-тест в начале обучения студентов и при его завершении. Так, на первом году зафиксированы положительные связи со статусом Достигнутой идентичности $(\rho=0,28, \mathrm{p}<0,01)$ и отрицательные - со статусом Предрешенной $(\rho=-0,29, p<0,01)$, а на втором - связи со статусом Достигнутой $(\rho=0,17, p<0,05)$ и Спутанной $(\rho=-0,22, p<0,01)$ идентичности. По-видимому, описание себя при помощи указания на какие-то будущие статусы или события в начале студенчества связано с Достигнутой 
идентичностью. На третьем курсе эта связь нарушается: никаких корреляций ни со статусом Достигнутой идентичности, ни с другими статусами у данного компонента не обнаружено. Однако к концу обучения в вузе связи появляются вновь: на уровне тенденции со статусом Достигнутой $(\rho=0,16$, $\mathrm{p}<0,05)$ и более тесная - со статусом Спутанной $(\rho=-0,21, \mathrm{p}<0,01)$ идентичности.

Мы не зафиксировали никаких связей между выделяемой нами интегральной идентичностью с малыми группами и статусами эгоидентичности. Возможно это связано с низкой динамикой данного компонента в целом.

Обращают на себя внимание тесные связи между экзистенциальным компонентом идентичности и статусами эго-идентичности практически на всем протяжении обучения студентов в вузе. Начиная с первого курса положительная связь существует со статусом Достигнутой идентичности $(\rho=0,27, p<0,01)$ и отрицательная - со статусом Спутанной $(\rho=-0,2$, $\mathrm{p}<0,01)$ идентичности. Однако уже на втором курсе связь сохраняется только со статусом Спутанной идентичности $(\rho=-0,2, p<0,01)$, а на уровне тенденции - со статусом Предрешенной идентичности ( $\rho=-0,36$, $\mathrm{p}<0,01)$. К третьему курсу, хотя происходит снижение выраженности статуса Достигнутой идентичности и роста статуса Спутанной, мы обнаружили положительную корреляцию данного компонента с первым ( $\rho=0,19$, $\mathrm{p}<0,01)$ и отрицательную - со вторым $(\rho=-0,21, \mathrm{p}<0,01)$. Можно предположить, что описание себя при помощи экзистенциальных категорий, как и описание себя в категориях личностных, оказывается своеобразной реакцией на рост спутанности, неопределенности идентичности.

\section{Обсуждение результатов}

Прежде всего, как и было отмечено выше, динамика различных компонентов в юношеском возрасте не отличается изменчивостью. Выявленный нами характер соотношения различных компонентов идентичности в целом соотносится с предлагаемой другими авторами. Так, Г.Б. Мазилова, изучая компоненты идентичности россиян в целом, приводила сходное распределение: на долю профессиональной, ролевой позиции приходилось $13,9 \%$, восприятие себя членом семьи - 8,2\%, рефлексивную самоидентичность - от $17 \%$ до 29,9\% [12]. Полученные нами ранее результаты [13-15] также соответствуют выявленным в ходе данного исследования.

Касаясь доли и особенностей динамики отдельных компонентов, отметим следующее. Целый ряд авторов (например, Т.В. Мищенко [16], П.В. Смирнова [17], Е.Е. Трандина [18], М.С. Коданева [19]) отмечают характерную динамику учебно-профессиональной идентичности в юношеском возрасте: в период с 4-го по 6-й семестр (2-3-й курс) наблюдается значимое понижение принятия себя как профессионала, что свидетельствует о наличии кризисного периода по этому параметру профессиональной идентичности, а затем, с 4-го по 8-й семестр (3-4-й курс), отмечается 
ее рост, связанный с переходом от учебно-академической идентичности к учебно-профессиональной. По мнению ряда авторов (например, Н.A. Bosma [20]), в раннем юношеском возрасте учебная идентичность является ключевым аспектом самоопределения и основой будущего планирования своей жизни [6]. Действительно, именно в эти периоды мы зафиксировали рост соответствующего компонента идентичности и только затем - ее снижение.

Стабильность коммуникативного и полоролевого компонентов описывается в работах I. de Goede et al. [21], M. Helsen et al. [22]. Если в начале юношеского возраста отношения с друзьями и приятелями составляют основу межличностной (relational) идентичности, то в дальнейшем, при переходе к ранней взрослости, ее актуальность снижается. Для этого периода характерно доминирование либо идентификации со своей ролью романтического партнера [22], либо семейного компонента идентичности. Действительно, семейная идентичность оказывается одной из доминирующих в юношеском возрасте. Вслед за Е. Crocetti, проводившей свои исследования на итальянской выборке [6], мы можем предположить, что данная идентичность является чрезвычайно важной для испытуемых, проживающих в России, - отсюда и ее доминирование, а не, скажем, полоролевого компонента, как в исследованиях, проводимых, например, в Великобритании.

Во-вторых, как и отмечалось выше, динамика статусов эгоидентичности у студентов, измеренная нами при помощи методики СЭИтест, несколько отличается от смены статусов, предложенной в модели Дж. Марсиа: статус диффузной (спутанной) идентичности - мораторий статус Предрешенной идентичности - статус Достигнутой идентичности (по [5]). На наш взгляд, это связано с тем, что, во-первых, в модели Е.Л. Солдатовой не выделяется статус моратория. Во-вторых, наши наблюдения ограничиваются 4-летним периодом и завершаются вместе с окончанием студентами бакалавриата, т.е. в момент, драматический для их идентичности. Можно предположить, что вслед за снижением выраженности Достигнутой идентичности наступит статус моратория и затем - через Предрешенную идентичность - испытуемые вновь обретут статус Достигнутой идентичности уже в новом для себя статусе - как представители определенной профессии или как студенты-магистранты. Тем не менее смена статусов идентичности у студентов в нашем исследовании не оказалась столь линейной и столь явно выраженной.

В-третьих, мы обнаружили специфику связей между компонентами идентичности и статусов эго-идентичности в различные периоды времени. Если на первом этапе обучения большинство связей компонентов идентичности приходится на статус Достигнутой идентичности, то в дальнейшем они в большей степени связаны со статусом Предрешенной и Спутанной (второй срез), Спутанной (третий срез) идентичности. Кроме того, отдельные ее компоненты оказываются в большей степени связаны с определенным статусом (например, связь личностного компонента и статуса Спутанной идентичности в первые три года обучения в вузе). 
С одной стороны, определено, что испытуемые с определенным статусом идентичности более склонны описывать себя в категориях соответствующего компонента идентичности. С другой стороны, на наш взгляд, все-таки неправомерно утверждать, что, коррелируя с определенным статусом идентичности, соответствующий компонент принимает данный статус. Возможно, испытуемый, идентичность которого находится в одном из статусов, более склонен описывать себя при помощи конкретных самоописаний, свойственных тому или иному компоненту - эти связи и зафиксированы в ходе корреляционного анализа. Собственно, связь между определенным статусом идентичности и ассоциациями, возникающими по поводу ряда понятий, и лежали в основе методики Л.Б. Шнейдер. Однако данные конкретные самокатегоризации, связанные со статусами идентичности, нами не выявлялись.

Сравнивая полученные корреляции с результатами зарубежных исследований, отметим следующее. Во-первых, в работе [5] Wim Meeus указывает на стабильность статусов этнической идентичности в начале юношеского возраста, а также на развитие статусов у личностной идентичности. Действительно, мы не зафиксировали почти никаких корреляций между изменяющимися статусами эго-идентичности и этническим компонентом. Однако это, по нашему мнению, связано скорее с достаточно низкой выраженностью соответствующего компонента, нежели со стабильностью его статуса.

С другой стороны, Meeus указывает на развитие статусов у личностного компонента. Однако, во-первых, согласно нашим предыдущим исследованиям [23], данный компонент имеет тенденцию возрастать в ситуации кризиса идентичности, а, во-вторых, в нашем исследовании он последовательно коррелирует со статусом Спутанной идентичности, т.е. его развития не происходит.

В работе Е. Crocetti отмечается, что начало юношеского возраста связано с изменением отношений с близкими друзьями и сменой статусов соответствующей идентичности. По Crocetti, юноши попадают в новую среду и знакомятся с новыми людьми; их друзья могут пойти в другой университет, что, вероятно, повлияет на дружбу. Отсюда пересмотр соответствующих обязательств и поиск новых связей и отношений. Однако мы не зафиксировали никаких корреляций шкал методики СЭИ-тест ни с Коммуникативным компонентом идентичности (самоописание испытуемого при взаимодействии с друзьями и приятелями), ни с Интегральной идентичностью с малыми группами (самоописание испытуемого как члена неформальных групп). Получается, что изменение статусов эго-идентичности не связано с самоописаниями в соответствующих категориях.

\section{Выводы}

Таким образом, по результатам данного исследования можно сделать следующие выводы: 
- динамика различных компонентов идентичности в юношеском возрасте не отличается изменчивостью. Основная динамика приходится на учебно-профессиональный компонент (снижается к 3-му курсу, однако затем резко повышается), перспективный (повышается к окончанию вуза), семейный (устойчиво растет на всем протяжении студенчества) и описание себя в терминах членства в различных неформальных группах (снижается к окончанию вуза);

- динамика статусов эго-идентичности у студентов, измеренная при помощи методики СЭИ-тест, несколько отличается от смены статусов, предложенной в модели Дж. Марсиа: статус диффузной (Спутанной) идентичности - мораторий - статус Предрешенной идентичности - статус Достигнутой идентичности (по Meeus, 2011). Кризис структуры эгоидентичности наблюдается у студентов между 2-м и 3-м курсами. При этом между 1-м и 2-м, наоборот, наблюдается снижение выраженности статуса Предрешенной идентичности, связанной, возможно, с постепенным вхождением студентов в учебный процесс в частности и в новую для себя социальную роль вообще, однако это снижение компенсируется постепенным ростом статуса Спутанной идентичности;

- существуют специфические связи между компонентами идентичности и статусами эго-идентичности в различные периоды времени. Если на первом этапе обучения большинство связей компонентов идентичности приходится на статус Достигнутой идентичности, то в дальнейшем они в большей степени связаны со статусом Предрешенной и Спутанной (второй срез), Спутанной (третий срез) идентичности. Кроме того, отдельные ее компоненты оказываются в большей степени связаны с определенным статусом (например, связь личностного компонента и статуса Спутанной идентичности в первые три года обучения в вузе).

\section{Литература}

1. Антонова И.В. Проблема личностной идентичности // Психология самосознания / под ред. Д.Я. Райгородского. Самара, 2000. С. 572-590.

2. Marcia J.E. Ego identity status: relationship to change in self-esteem, «general maladjustment», and authoritarianism // Journal of personality. 1967. Vol. 35. P. 118-133.

3. Crocetti E., Schwartz S.J., Fermani A., Meeus W. The Utrecht-Management of Identity Commitments Scale (U-MICS) Italian Validation and Cross-National Comparisons // European Journal of Psychological Assessment. 2010. Vol. 26 (3). P. 172-186. DOI: $10.1027 / 1015-5759 / \mathrm{a} 000024$.

4. Meeus W., van de Schoot R., Keijsers L., Schwartz S.J., Branje S. On the Progression and Stability of Adolescent Identity Formation: a Five-Wave Longitudinal Study in Early-toMiddle and Middle-to-Late Adolescence // Child Development. 2010. Vol. 81, № 5. P. $1565-1581$.

5. Meeus W. The Study of Adolescent Identity Formation 2000-2010: a Review of Longitudinal Research // Journal of research on adolescence. 2011. № 21 (1). P. 75-94.

6. Crocetti E., Fermani A., Pojaghi B., Meeus W. Identity Formation in Adolescents from Italian, Mixed, and Migrant Families // Child Youth Care Forum. 2011. Vol. 40. P. 7-23. DOI: $10.1007 / \mathrm{s} 10566-010-9112-8$.

7. Шнейдер Л.Б. Личностная, гендерная и профессиональная идентичность: теория и методы диагностики. М. : Моск. психол.-соц. ин-т, 2007, 234 с. 
8. Солдатова Е.Л. Нормативные кризисы развития личности взрослого человека : автореф. дис. ... д-ра психол. наук. Екатеринбург, 2007. 50 с.

9. Turan M. B., Koç K., Karaoglu B. Analysis of Ego Identity Status of School of Physical Education and Sports // Universal Journal of Educational Research. 2017. Vol. 5 (9). P. 1580-1588. DOI: 10.13189/ujer.2017.050915.

10. Sanchez D. Racial identity attitudes and ego identity statuses in Dominican and Puerto Rican college students // Journal of College Student Development. 2013. № 54 (5). P. 497-510. DOI: 10.1353/csd.2013.0077.

11. Kuhn M.H., McPartland T.S. The Empirical Investigation of Self-attitude // American Sociological Review. 1954. Vol. 19. P. 68-76.

12. Мазилова Г.Б. Динамика социальной идентичности личности в современном обществе : дис. .... канд. психол. наук. Ярославль, 2006. 203 с.

13. Кузьмин М.Ю. Сравнение идентичности младших школьников, подростков и лиц юношеского возраста // Сибирский психологический журнал. 2015. № 58. С. 61-75. DOI: $10.17223 / 17267080 / 58 / 4$.

14. Кузьмин М.Ю. Особенности динамики идентичности младших школьников, подростков и лиц юношеского возраста // Сибирский психологический журнал. 2016. № 62. C. 54-66. DOI: 10.17223/17267080/62/5.

15. Кузьмин М.Ю. Сравнение идентичности и ее динамики у младших школьников, подростков и лиц юношеского возраста // Российский психологический журнал. 2017. T. 14, № 2. C. 67-89. DOI: 10.21702/rpj.2017.2.4.

16. Мищенко Т.В. Становление профессиональной идентичности у студентов педагогического вуза : автореф. дис. ... канд. психол. наук. Ярославль, 2005. 23 с.

17. Смирнова П.В. Рефлексивная методика исследования психологических особенностей профессиональной идентичности личности на примере профессии «Психолог» // Прикладная психология и психоанализ. 2006. № 4. С. 23-30.

18. Трандина Е.Е. Становление профессиональной идентичности у студентов юридического вуза : дис. ... канд. психол. наук. Ярославль, 2006. 225 с.

19. Коданева М.С. Становление профессиональной идентичности психологов уголовноисполнительной системы (ценностно-смысловой аспект) // Вестник Костромского государственного университета им. Н.А. Некрасова. 2007. Т. 13, № 6. С. 33-38.

20. Bosma H.A. Identity evelopment in adolescents: Copingwith commitments // Unpublished doctoral dissertation. 1985. Unpublished doctoral dissertation, State University, Groningen, the Netherlands.

21. De Goede I., Branje S., Meeus W. Developmental changes and gender differences in adolescents' perceptions of friendships // Journal of Adolescence. 2009. Vol. 32. P. 11051123.

22. Helsen M., Vollebergh W., Meeus W. Social support from parents and friends and emotional problems in adolescence // Journal of Youth and Adolescence. 2000. Vol. 29. P. 319-335.

23. Кузьмин М.Ю., Конопак И.А. Эмпирическое изучение критериев кризиса идентичности студентов старших и младших курсов // Известия Иркутского государственного университета. Сер. Психология. 2014. Т. 8. С. 45-55.

Поступила в редакичию 06.05.2018 г.; принята 31.05.2018 г.

\section{Сведения об авторе:}

КУЗЬМИН Михаил Юрьевич, кандидат психологиеских наук, доцент кафедры общей психологии Иркутского государственного университета (Иркутск, Россия). E-mail: mirroy@mail.ru 


\section{DYNAMICS OF IDENTITY COMPONENTS RELATIONS AND ITS STATUS AMONG STUDENTS}

Sibirskiy Psikhologicheskiy Zhurnal - Siberian journal of psychology, 2018, 69, 69-84.

DOI: 10.17223/17267080/69/4

Mikhail Y. Kuzmin, Irkutsk State University (Irkutsk, Russian Federation). E-mail: mirroy@mail.ru

Keywords: ego-identity; identity; youth; students; Twenty Statements Test; identity status.

The authors examine native and foreign approaches to the dynamics of identity statuses and its components. We have analyzed the modern approaches to the identity theory by James Marcia and further development of his ideas (Meeus, 2001; Crocetti et al., 2008; Crocetti, Rubini, and Meeus, 2008), selection of new, intermediate identity statuses (early closure, searching moratorium etc.), as well as the tools for their research (Utrecht- Management of Identity Commitments Scale (U-MICS). The native approach to this problem is also analyzed (Schneider, Soldatova, etc.).

The problem is understudied in Russian science. Using the Twenty Statements Test by Kuhn M. H. and McPartland and SEI-test by Soldatova E.L. on the sample of 250 subjects (112 males and 138 females) the authors investigate the peculiarities of relations among different identity components and ego-identity status. First, we revealed that the dynamics of different identity components in adolescence is not variable. The major part of the dynamics accrues to the educational and professional component (it decreases by the third year of studying, than increases again), to perspective component (increases by graduation), to family (increases steadily) and self-description in the terms of belonging to different informal groups (decreases by graduation).

Second, the dynamics of ego-identity statuses, measured by SEI-test, differs from the status change, described by Marcia. The identity statuses are identity diffusion, moratorium, foreclosure and identity achievement. The crisis of ego-identity structure of students is revealed between second and third years of study. Between first and second years the foreclosure status is less expressed. It may be related with students' gradual coming into educational process and into a new social role. But the decrease is offset by gradual increase of identity diffusion status.

Third, there are specific connections among identity components and ego-identity statuses in different periods of time. At the first stage of study the major part of identity components relations coincides with identity achievement, later they correspond to foreclosure and identity diffusion statuses. Moreover, particular components turn out to be related in greater degree with a definite status (e.g. the personal component and identity diffusion status during the first three years of university).

\section{References}

1. Antonova, I.V. (2000) Problema lichnostnoy identichnosti [The Problem of Personal Identity]. In: Raygorodskiy, D.Ya. (ed.) Psikhologiya samosoznaniya [Psychology of SelfConsciousness]. Samara: Bakhrakh-M. pp. 572-590.

2. Marcia, J.E. (1967) Ego identity status: relationship to change in self-esteem, "general maladjustment", and authoritarianism. Journal of Personality. 35. pp. 118-133. DOI: 10.1111/j.1467-6494.1967.tb01419.x

3. Crocetti, E., Schwartz, S.J., Fermani, A. \& Meeus, W. (2010) Utrecht-Management of Identity Commitments Scale (U-MICS) Italian Validation and Cross-National Comparisons. European Journal of Psychological Assessment. 26(3). pp. 172-186. DOI: 10.1027/1015-5759/a000024

4. Meeus, W., van de Schoot, R., Keijsers, L., Schwartz, S.J. \& Branje, S. (2010) On the Progression and Stability of Adolescent Identity Formation: a Five-Wave Longitudinal Study 
in Early-to-Middle and Middle-to-Late Adolescence. Child Development. 81(5). pp. 1565-1581. DOI: 10.1111/j.1467-8624.2010.01492.x

5. Meeus, W. (2011) The Study of Adolescent Identity Formation 2000-2010: a Review of Longitudinal Research. Journal of Research on Adolescence. 21(1). pp. 75-94. DOI: 10.1111/j.1532-7795.2010.00716.x

6. Crocetti, E., Fermani, A., Pojaghi, B. \& Meeus, W. (2011) Identity Formation in Adolescents from Italian, Mixed, and Migrant Families. Child Youth Care Forum. 40. pp. 7-23. DOI: $10.1007 / \mathrm{s} 10566-010-9112-8$.

7. Shneyder, L.B. (2007) Lichnostnaya, gendernaya i professional'naya identichnost': teoriya $i$ metody diagnostiki [Personal, gender and professional identity: theory and methods of diagnosis]. Moscow: Moscow Psychological and Social Institute.

8. Soldatova, E.L. (2007) Normativnye krizisy razvitiya lichnosti vzroslogo cheloveka [Normative crises in the development of an adult personality]. Abstract of Psychology Dr. Diss. Ekaterinburg.

9. Turan, M. B., Koç, K. \& Karaoglu, B. (2017) Analysis of Ego Identity Status of School of Physical Education and Sports. Universal Journal of Educational Research. 5(9). pp. 1580-1588. DOI: $10.13189 /$ ujer.2017.050915

10. Sanchez, D. (2013) Racial identity attitudes and ego identity statuses in Dominican and Puerto Rican college students. Journal of College Student Development. 54(5). pp. 497510. DOI: $10.1353 /$ csd.2013.0077

11. Kuhn, M.H. \& McPartland, T.S. (1954) The Empirical Investigation of Self-attitude. American Sociological Review. 19. pp. 68-76. DOI: 10.2307/2088175

12. Mazilova, G.B. (2006) Dinamika sotsial'noy identichnosti lichnosti v sovremennom obshchestve [Dynamics of the social identity of the individual in modern society]. Psychology Cand. Diss. Yaroslavl.

13. Kuzmin, M.Yu. (2015) Comparison of identities of junior pupils, teenagers and young people. Sibirskiy psikhologicheskiy zhurnal - Siberian Journal of Psychology. 58. pp. 6175. (In Russian). DOI: 10.17223/17267080/58/4

14. Kuzmin, M.Yu. (2016) Peculiarities of identity dynamics of schoolchildren, teenagers and young people. Sibirskiy psikhologicheskiy zhurnal - Siberian Journal of Psychology. 62. pp. 54-66. (In Russian). DOI: 10.17223/17267080/62/5

15. Kuzmin, M.Yu. (2017) Sravnenie identichnosti i ee dinamiki u mladshikh shkol'nikov, podrostkov i lits yunosheskogo vozrasta [Comparison of identity and its dynamics in younger schoolchildren, teenagers and adolescents]. Rossiyskiy psikhologicheskiy zhurnal-Russian Psychological Journal. 14(2). pp. 67-89. DOI: 10.21702/rpj.2017.2.4.

16. Mishchenko, T.V. (2005) Stanovlenie professional'noy identichnosti u studentov pedagogicheskogo vuza [Formation of professional identity in students of a pedagogical university]. Abstract of Psychology Cand. Diss. Yaroslavl.

17. Smirnova, P.V. (2006) Refleksivnaya metodika issledovaniya psikhologicheskikh osobennostey professional'noy identichnosti lichnosti na primere professii "Psikholog" [Reflexive methods of research of psychological features of professional identity of an individual on the example of the profession "Psychologist"]. Prikladnaya psikhologiya $i$ psikhoanaliz. 4. pp. 23-30.

18. Trandina, E.E. (2006) Stanovlenie professional'noy identichnosti u studentov yuridicheskogo vuza [Formation of professional identity in students of a law school]. Psychology Cand. Diss. Yaroslavl.

19. Kodaneva, M.S. (2007) Stanovlenie professional'noy identichnosti psikhologov ugolovnoispolnitel'noy sistemy (tsennostno-smyslovoy aspekt) [Formation of the professional identity of psychologists of the criminal executive system (the value-semantic aspect)]. Vestnik Kostromskogo gosudarstvennogo universiteta im. N.A. Nekrasova - Vestnik of Kostroma State University. 13(6). pp. 33-38.

20. Bosma, H.A. (1985) Identity in adolescents: Copingwith commitments. Unpublished doctoral dissertation. State University, Groningen, the Netherlands. 
21. De Goede, I., Branje, S. \& Meeus, W. (2009) Developmental changes and gender differences in adolescents' perceptions of friendships. Journal of Adolescence. 32. pp. 11051123. DOI: $10.1016 /$ j.adolescence.2009.03.002

22. Helsen, M., Vollebergh, W. \& Meeus, W. (2000) Social support from parents and friends and emotional problems in adolescence. Journal of Youth and Adolescence. 29. pp. 319335. DOI: $10.1023 / \mathrm{A}: 1005147708827$

23. Kuzmin, M.Yu. \& Konopak, I.A. (2014) Empiricheskoe izuchenie kriteriev krizisa identichnosti studentov starshikh i mladshikh kursov [An empirical study of criteria for the crisis of identity of students in senior and junior years]. Izvestiya Irkutskogo gosudarstvennogo universiteta. Ser. Psikhologiya. 8. pp. 45-55.

Received 06.05.2018; Accepted 31.05.2018 